\title{
La atribución del uso de la vivienda en supuestos de guarda y custodia compartida: análisis de la doctrina jurisprudencial
}

\author{
The attribution of the use of housing in guardian assumptions \\ and shared custody: analysis of jurisprudential doctrine
}

\author{
María José Pardo Pumar ${ }^{1}$ \\ UNED \\ e-mail (calibri 12 normal)
}

Recepción: 12/12/2018 Revisión: 18/12/2019 Aceptación: 12/02/2019 Publicación: 01/06/2019

\section{Resumen}

Procede afirmar que uno de los grandes caballos de batalla de la guarda y custodia compartida lo constituye la determinación de la atribución del uso de la vivienda familiar, si es que al fijarse un régimen de custodia compartida podemos continuar hablando de la existencia de vivienda familiar como tal. A pesar de que este tema se configura, como he dicho, como uno de los grandes caballos de batalla en los procedimientos judiciales sobre guarda y custodia compartida, la realidad es que en España carecemos de regulación legal expresa al respecto siendo el único punto de referencia, tal y como se determinó en la S.T.S. de 24 de octubre de 2014, el apartado 2 del artículo 96, el cual debe aplicarse por analogía a estos supuestos.

En este artículo se analiza pues la doctrina jurisprudencial en materia de atribución de la vivienda en dicho régimen de guarda y custodia.

Palabras claves: Guarda y custodia compartida; domicilio familiar; interés del menor. U.N.E.D.

\footnotetext{
${ }^{1}$ Abogada de familia, Doctoranda del programa de Doctorado en derecho y ciencias sociales de la
} 


\begin{abstract}
It is appropriate to affirm that one of the great workhorses of shared custody is the determination of the attribution of the family house, if, in establishing a shared custody regime, we can continue talking about the existence of a family house as such. Although this issue is configured, as I said, as one of the great workhorses in the judicial proceedings on guardianship and shared custody the reality is that in Spain we lack legal regulation expresses in this regard being the only point of reference, as determined in the STS of October 24, 2014, paragraph 2 of Article 96, which must be applied by analogy.
\end{abstract}

In this article we analyze the jurisprudential doctrine of the Supreme Court regarding the attribution of housing in said custody regime.

Keywords: Shared custody; family house; child's interest

\title{
Sumario
}

1. PRELIMINARES.

2. DOCTRINA JURISPRUDENCIAL DE ATRIBUCION DE LA VIVENDA EN CASO DE GUARDA Y CUSTODIA COMPARTIDA.

2.1. La inaplicación del artículo 96.1 del código civil y la necesaria aplicación analógica del 96.2 en los supuestos de guarda y custodia compartida.

2.2. Intereses que deben ser ponderados por el juez para resolver sobre atribución del uso de la vivienda familiar en los casos de guarda y custodia compartida.

3. LA LIMITACIÓN TEMPORAL DE LA ATRIBUCIÓN DEL USO EN LOS SUPUESTOS DE GUARDA Y CUSTODIA COMPARTIDA.

4.CONCLUSIONES.

5. INDICE DE LAS RESOLUCIONES CITADA

6. BIBLIOGRAFIA

\section{PREMILINARES}

La atribución de la vivienda familiar en los casos de crisis matrimoniales ha sido, es y será causa de fricción entre las dos partes en conflicto en los procedimientos de familia, en este caso entre los dos progenitores.

El artículo 96 del Código Civil, en su apartado 1, contempla la solución a la atribución de la vivienda familiar cuando la guarda y custodia se atribuye en exclusiva a uno de los progenitores. Así determina lo siguiente: "En defecto de acuerdo con los cónyuges aprobado 
por el juez, el uso de la vivienda familiar y de los objetos de uso ordinario en ella corresponden a los hijos y al cónyuge en cuya compañía queden."

La Ley 15/2005 de 8 de julio de modificación del Código Civil y de la Ley de Enjuiciamiento Civil en materia de separación y divorcio es la primera norma jurídica de nuestro ordenamiento que se refiere de manera expresa a la guarda y custodia compartida en los casos de crisis matrimonial.

Dicha Ley dio, en efecto, nueva redacción al artículo 92 del Código civil , para introducir lo que el texto normativo denomina, en su exposición de motivos, como guarda y custodia conjunta (lo que habitualmente se denomina custodia compartida). Así el apartado quinto de este artículo introdujo la posibilidad de que el Juez acordase la guarda y custodia compartida de mutuo acuerdo -cuando ambos progenitores así lo acuerden en convenio regulador o lleguen a dicho acuerdo en el transcurso del procedimiento -.

Junto a esta guarda y custodia compartida de mutuo acuerdo contempla también la Ley la posibilidad, a través del apartado 8 del artículo 92, de la guarda y custodia contenciosa -es decir la impuesta por el Juez- si bien dota a esta, siempre en base al favor filii, de una serie de cautelas, en concreto tres: la primera, que necesariamente debe ser solicitada por uno de los progenitores, con lo que descarta la guarda y custodia de oficio, la segunda, que se adopte en beneficio del interés del menor, siendo este el único medio por el que se garantizaría el beneficio del menor por lo que la configura como una mediad excepcional (veremos la evolución de la jurisprudencia del Tribunal Supremo en este aspecto) y tercera, que existiese informe "favorable" del Ministerio fiscal. Término este, el de favorable, que fue declarado inconstitucional y por ende nulo por la sentencia del Tribunal Constitucional de 17 de octubre de 2012 .

Esta ley respondía a las nuevas necesidades sociales especialmente por el incremento de la interposición ante los juzgados de familia de demandas instando la atribución de una guarda y custodia compartida. Ley que, por otra parte, tal y como afirma Beatriz Escudero Berzal, "adolece de importantes carencias en cuestiones fundamentales" y es que, se limita a introducir la posibilidad de la guarda y custodia compartida sin regular ningún otro aspecto derivado de la adopción de dicho régimen, así no se regula la pensión de alimentos de los hijos menores, ni tampoco la atribución del uso de la vivienda familiar.

Así, llegados a este punto, el de introducción de la guarda y custodia compartida como régimen posible en nuestro Código Civil, la práctica judicial dio lugar a numerosos interrogantes que la jurisprudencia de nuestro Tribunal Supremo fue solventando poco a poco entre ellos y, en lo que aquí es objeto de análisis, el de la atribución de la vivienda.

Los criterios de atribución de la vivienda familiar han venido siendo cuatro:

1. Acuerdo entre los cónyuges. 
2. El tradicional y prioritario contemplada en el ya citado apartado primero del artículo 96 del CC, es decir atribución al progenitor bajo cuya guarda quedasen los hijos.

3. El del interés más necesitado de protección. Criterio que se aplica en ausencia de hijos menores y que determina la atribución del uso al progenitor más necesitado de protección y por tiempo prudencial.

Hasta ahora resultaba de aplicación el apartado 1 del artículo 96 del Código civil, la regla es de atribución de la vivienda familiar al progenitor custodio por entender que los menores son el interés más necesitado de protección. Si bien los Tribunales tienden a apartarse cada vez más de este criterio tradicional de atribución para tratar de ponderar lo interés en conflicto en cada caso concreto. Pero en el régimen de guarda compartida el problema va más allá y es que no podemos hablar ya propiamente de una vivienda familiar y que el apartado 1 del artículo 96 no puede resultar de aplicación por cuanto los hijos no quedan en compañía de uno sólo de los progenitores sino de los dos.

La realidad es que, a diferencia de lo que sucede en determinadas C.C.A.A., no existe a fecha de hoy normativa alguna, de carácter especifico, que determine las reglas de atribución de la vivienda familiar en los casos de custodia compartida con todas las variantes que esta puede presentar. Entre estas CCAA que sí han regulado la custodia compartida se encuentran Navarra, Aragón, Cataluña, Valencia y País Vasco.

a) Aragón fue la primera comunidad autónoma en regular la custodia compartida y lo hizo a través de la aprobación de la Ley 2/2010, de 26 de mayo, de igualdad en las relaciones familiares ante la ruptura de convivencia de los padres, la cual establecía como preferente el sistema de guarda y custodia compartida. Ahora bien, esta ley fue derogada por Decreto Legislativo 1/2011, de 22 de marzo, del Gobierno de Aragón, por el que se aprueba, con el título de Código de Derecho Foral de Aragón, el texto refundido de las leyes civiles aragonesas, el cual optando por el modelo de guarda y custodia compartida como preferente. Regula la guarda y custodia compartida en el artículo 80 y en el 81 lo relativo a la atribución de la vivienda familiar tanto en los supuestos de guarda y custodia exclusiva como compartida así el apartado primero de su artículo 81 determina que : En los casos de custodia compartida, el uso de la vivienda familiar se atribuirá al progenitor que por razones objetivas tenga más dificultad de acceso a una vivienda y, en su defecto, se decidirá por el Juez el destino de la vivienda en función del mejor interés para las relaciones familiares. Es decir se atiende al criterio del intereses más necesitado de protección -que en este caso se entiende que será la de aquel progenitor que tenga más dificultades para acceder a una vivienda- y en todo caso la atribución de la vivienda a uno de los progenitores se consagra como temporal sujeto a un plazo de tiempo, tiempo que será el pactado entre los progenitores y en su defecto será evidentemente el Juez 
quien determine la atribución del uso de la vivienda siempre en atención a las circunstancias concretas de cada familia .

b) Cataluña, Ley 25/2010, de 29 de julio, del Libro segundo del Código civil de Cataluña, relativo a la persona y a la familia, la cual regula el denomina Plan de parentalidad que debe ser elaborado por los progenitores en caso de existir acuerdo entre ellos, la regulación relativa a las medidas en relación a los hijos se encuentra en la Sección segunda del Capitulo III bajo la rúbrica Cuidado de los hijos : Ley que no emplea -en mi modesta opinión de manera más que correcta -el termino de custodia compartida sino de ejercicio conjunto de responsabilidades parentales, estableciendo esta modalidad como preferente en caso de inexistencia de acuerdo entre los progenitores. Sí contempla esta normativa una regulación especifica de la atribución del uso de la vivienda en caso de guarda y custodia compartida de tal forma que en primer lugar esta se determinará por acuerdo entre los cónyuges y en su defecto se atenderá para atribuir su uso al interés más necesitado de protección y dicha atribución del uso lo será siempre de forma temporal, introduciendo la posibilidad de prórroga que será igualmente limitada en el tiempo.

c) Navarra, continuando con la exposición de la regulación foral de la materia Comunidad foral de Navarra cuenta con la Ley foral 3/2011, de 17 de marzo, sobre custodia de los hijos en los casos de ruptura de la convivencia de los padres, cuyo artículo 3 contempla los dos posibles regímenes de guarda y custodia a adoptar tanto el individual o exclusivo de uno solo de los progenitores como el de custodia compartida no estableciendo ninguno de ellos como preferente Ahora bien he de decir que esta Ley, a diferencia del Código foral de Aragón y de la Ley catalana, no contempla, en lo que al tema objeto de este artículo se refiere, ningún criterio en cuanto a al atribución de la vivienda en los casos de guarda y custodia compartida, si bien sí que determina los factores a los que el juez debe atender para conceder uno $u$ otro tipo de custodia siempre atendiendo al interés del menor y a que ele ejercicio de los derechos y deberes de los padres para con los hijos puede ejercitarse en situación de equidad, pero en ningún caso otorgan carácter de preferente a uno u otro tipo de custodia.

d) Valencia: En a la comunidad valenciana se regulaba la guarda y custodia compartida por la Ley 5720011, de 1 de abril, de relaciones familiares de los hijos e hijas cuyos progenitores no conviven. Dicha Ley que establecía como sistema preferente en caso de inexistencia de acuerdo entre los progenitores la guarda y custodia compartida ha sido declarada inconstitucional y por lo tanto anulada por el Tribunal constitucional a través de su Sentencia 192/2016, de 16 de noviembre, por falta de competencia autonómica en la materia. 
e) País Vasco, ha sido el último en regular la custodia compartida y lo ha hecho a través de la Ley $7 / 2015$, de 30 de junio, de relaciones familiares en supuestos de separación o ruptura de los progenitores. Dicha ley consagra la custodia compartida como un derecho de las personas menores, dando preferencia por lo tanto a la custodia compartida sobre la exclusiva en caso de desacuerdo entre los padres, pero en ningún caso se podrá acordar de oficio. Contempla la ley en el apartado 6 de su artículo 9 los criterios que el juez deberá tener en cuenta para adoptar la custodia compartida. Introduce, en lo que aquí nos interesa una regulación de la atribución del uso de la vivienda en caso de guarda y custodia compartida, en concreto en los apartado 4 y 5 del artículo 12 , evidentemente regirán en defecto de acuerdo, en virtud del cual si no hiciese un distribución de uso por periodos alternos se atribuirá en base a motivos de necesidad, esto es al que tuviera mayores dificultades de acceso a otra vivienda, siempre y cuando esto fuera compatible con el interés del menor y con carácter temporal. Novedoso resulta en esta ley el que introduce un plazo máximo para la atribución del uso por motivos de necesidad, dicho plazo máximo es de dos años, si bien cabe prorroga que deberá necesariamente solicitarse con seis meses de antelación a la expiración del plazo máximo inicial.

f) De lo expuesto se desprende que a nivel nacional carecemos de normativa específica relativa a la guarda y custodia compartida, a sus diferentes especialidades y cuestiones controvertidas como son la atribución del uso de la vivienda y fijación de la pensión de alimentos a favor de los hijos menores. De ahí que a través de artículo analizaremos la evolución jurisprudencial a este respecto tomando como punto de partida la sentencia dictada por la Sala de lo Civil del Tribunal supremo de fecha 24 de octubre de 2014, número de sentencia 593/2014 que sienta criterio jurisprudencial para asignar el uso de la vivienda familiar al cónyuge no titular en los casos de custodia compartida.

\section{DOCTRINA JURISPRUDENCIAL DE ATRIBUCION DE LA VIVENDA EN CASO DE GUARDA Y CUSTODIA COMPARTIDA.}

Como bien indica la rubrica de este apartado no trataremos aquí la atribución del uso de la vivienda familiar en los casos de guarda y custodia exclusiva ni tampoco de aquellos en los que exista acuerdo entre los progenitores al respecto, limitándonos a la atribución del uso en la guarda y custodia compartida cuando no existe acuerdo entre los progenitores.

\subsection{La inaplicación del artículo 96.1 del Código civil y la necesaria aplicación analógica del 96.2 en los supuestos de guarda y custodia compartida.}

El apartado primero del artículo 96 del Código civil regula la atribución del uso de la denominada vivienda familiar en los supuestos de crisis matrimonial, así es del tenor literal siguiente: "En defecto de acuerdo con los cónyuges aprobado por el Juez, el uso de la vivienda 
familiar y de los objetos de uso ordinario en ella corresponde a los hijos y al cónyuge en cuya compañía quedan."

Ante la ya afirmada inexistencia de regulación legal, en cuanto a la atribución del uso de la vivienda familiar en caso de guarda y custodia compartida, es doctrina reiterada del Tribunal Supremo que no procede la aplicación de este apartado 1 del artículo 92 y entre otras cuestiones porque es evidente que en los sistemas de custodia compartida los hijos no quedan bajo la custodia de uno solo de los progenitores sino de los dos. Así lo afirma el Tribunal supremo en su sentencia de 24 de octubre de 2014, en su fundamento de derecho tercero que: "El Código civil ha incorporado modificaciones importantes en su artículo 92 en materia de atribución de guarda y custodia compartida (...). Lo que no hay es una regulación específica para adaptarla a esta nueva modalidad de custodia posiblemente por las variables que el sistema comporta." y continua "Lo cierto es que el artículo 96 establece como criterio prioritario, a falta de acuerdo entre los cónyuges, que el uso de vivienda familiar corresponde al hijo y al cónyuge en cuya compañía , lo que no sucede en el caso de la custodia compartida al no encontrarse los hijos en compañía de uno solo de los progenitores, sino de los dos. " es por ello que entiende nuestro alto Tribunal que en estos casos debe aplicarse analógicamente el párrafo 2 del artículo 96 que viene a regular la atribución de la vivienda familiar cuando uno de los hijos queda en compañía de un progenitor y el resto en compañía del otro progenitor y en estos casos la solución es que será el Juez quien deba resolver a quien y en qué modo atribuir el uso de la vivienda familiar.

Aplicación analógica que ya, con anterioridad, había sido sostenida de manera tácita por el Tribunal Supremo en su sentencia №:576/2014, de 22 de octubre de 2014 al sostener que : "Procede la estimación del motivo de acuerdo con el art. 96 del C. Civil, dado que adoptándose el sistema de custodia compartida, el hijo queda en compañía de ambos cónyuges(...)es decir la vivienda que fue familiar queda sin adscripción expresa dado que ambos padres tienen la custodia(...) "; aplicación analógica mantenida y reafirmada a lo largo de estos años por el Tribunal Supremo, así la STS de 6 de abril de 2016, en su fundamento de derecho tercero punto 3 determina que: "El código Civil ha incorporado modificaciones importantes en su artículo 92 en materia de atribución de la guarda y custodia compartida, según la redacción dada por la Ley 15/2005, de 8 de julio, y la declaración de inconstitucional y nulo el inciso "favorable" del informe del Ministerio fiscal (...). Pero no existe, como afirma la TS de 24 de octubre de 2014, una regulación específica para adaptarla a este régimen de custodia, en contra de los que sí han llevado a cabo otras legislaciones autonómicas (Cataluña, Aragón Valencia y recientemente el País Vasco. La sala, ante tal vacío en materia de atribución de la vivienda familiar, al no encontrarse los hijos en compañía de uno solo de los progenitores sino de los dos, ha entendido que debe aplicarse analógicamente el párrafo segundo del artículo 96 CC " pero esta sentencia va más allá de reafirmar la aplicación analógica del 96.2 del CC, pues consagrara la inexistencia de vivienda familiar propiamente dicha en los casos de custodia compartida en los que el menor resida en cada periodo en el domicilio de cada uno de los progenitores de ahí que ya no exista una residencia única sino dos. Aplicación analógica que también se recoge en otras muchas sentencias como por ejemplo la S.T.S de 23 de enero 
de 2017 que recoge la doctrina de la Sala de lo civil del Tribunal Supremo sobre la materia, o la STS N. 294/2017, de 24 de mayo o la de 22 de septiembre de 2017 o la STS N 268/2018, de 9 de mayo, de 2018. Todas ellas hacen referencia a la ausencia de regulación específica sobre la materia (a diferencia de determinadas comunidades autónomas), ausencia de regulación que lleva a la inaplicación del párrafo primero del artículo 96 del CC y a la necesaria aplicación analógica del párrafo segundo de dicho artículo.

\subsection{Intereses que deben ser ponderados por el juez para resolver sobre atribución del uso de la vivienda familiar en los casos de guarda y custodia compartida.}

Esta aplicación analógica, a la que nos acabamos de referir en el expositivo inmediatamente anterior, en la que es el Juez quien resuelva lo procedente en relación a la atribución del uso por la vía del párrafo 2 del artículo 96, se hace necesario una ponderación de los intereses que entran en juego, así lo determina nuestro alto Tribunal, entre otras en la ya citada Sentencia de 24 de octubre de 2014 , en la cual se constata que: "Ello obliga a una labor de ponderación de las circunstancias concurrentes en cada caso en cada caso con especial atención a dos factores: en primer lugar, al interés más necesitado de protección, que no es otro que aquel que permite compaginar los periodos de estancia de los hijos con sus dos padres. En segundo lugar, a si la vivienda que constituye domicilio familiar es privativa de uno de los cónyuges, de ambos o de un tercero. En ambos casos con la posibilidad de imponer una limitación temporal en la atribución de del uso, similar a la que se establece en el párrafo tercero para los matrimonios sin hijos..."

Es decir, necesariamente debe llevarse a cabo una ponderación de las circunstancias de cada caso, circunstancias a tener en cuenta que tal y como constata la doctrina jurisprudencial son:

1. Interés más necesitado de protección

2. Titularidad de la vivienda:

a. Ganancial/ de ambos progenitores.

b. Privativa de uno de los cónyuges.

c. De un tercero.

Estos criterios o intereses no son en modo alguno complementarios sino contrapuestos y en el caso de la custodia compartida se impone la necesidad de armonizarlos.

Respecto al primero de los criterios de atribución de la vivienda familiar, el interés más necesitado de protección, debemos de analizar qué se entiende por tal interés y este no es otro, tal y como determina, entre otras, la S.T.S. 183/2017, de 14 de marzo, que "aquel que 
permite compaginar los periodos de estancia de los hijos con sus dos padres". Esta delimitación, en mi modesta opinión, es del todo correcta y adecuada.

No se trata sólo de valorar el superior interés del menor de un modo aislado sino interés enfocada al adecuado cumplimiento por parte de uno de los progenitores-aquel que tenga más dificultades de acceder a una vivienda- del régimen de custodia compartida instaurado, quizás seria mas correcto decir encaminado a que se pueda dar efectividad al régimen de guarda y custodia de manera idónea.

Interés del menor que es un concepto jurídico indeterminado, de ahí que la labor de los Tribunales sea aún mas ardua se cabe para garantizar su prevalencia, ni el Código civil ni la Ley Orgánica de Protección Jurídica del Menor contienen una definición del mismo. Si bien el artículo 2 de la L.O.P.J.M. ha ido perfilándolo y así lo ha configurado como un derecho primordial de los menores, ofrece criterios de valoración de este y elementos de ponderación de dichos criterios. Interés del menor que debe inspirara la totalidad de las medidas que se adopten en relativas a los hijos menores, tal y como determina Gutiérrez Romero, al afirmar que "...podemos poner de relieve que todas las medidas relativas a los hijos menores de edad han de estar inspiradas en el superior interés de los hijos, procurando, ante todo, el beneficio o interés preferente de los menores en orden a su desarrollo personal integral, por encima de los legítimos intereses de sus progenitores". Concepto este, el del interés del menor, esencial por cuanto no podemos olvidar que tal y como indica el TS en sus Sentencia de 4 de abril de 2018 el derecho a la atribución del uso de la vivienda familiar ha sido configurado pro el artículo 96 como una medida de protección de los menores. Medida esta que no tiene en modo alguno una finalidad expropiatoria.

Y enlazando con el último inciso del párrafo anterior entramos ya en el segundo de los criterios para la atribución del uso de la vivienda familiar es el de la TITULARIDAD de la que fue vivienda familiar, y es que como dice el Tribunal Supremo en su sentencia de 18 de abril de 2018 la atribución de la vivienda como derecho de los menores para su protección no tiene ni puede tener en modo alguno una finalidad expropiatoria, y por ello necesariamente debe ponderarse en su justa medida con los derechos del titular de la vivienda, especialmente si esta es privativa de uno de los cónyuges o de un tercero. Es una labor que la STS593/2014, de 24 de octubre define de armonización de intereses contrapuestos: el del titular de la vivienda y el del hijo a comunicarse con su madre en otra vivienda.

Ponderación de interés que debe llevar necesariamente a una limitación de la atribución del uso bien durante un plazo de tiempo razonable para que le progenitor al que le ha sido atribuido el uso pueda acceder a una vivienda digna en donde desarrollar el régimen de custodia con sus hijos en los periodos que le corresponda, bien hasta que se proceda la efectiva liquidación de gananciales. 


\section{LA LIMITACION TEMPORAL DE LA ATRIBUCION DEL USO DE LA VIVIENDA.}

Es evidente que la limitación o no en el tiempo de la atribución del uso de la vivienda dependerá en gran medida del tipo de atribución ante la que nos encontremos, así si es de mutuo acuerdo serán los cónyuges quienes determinen o no esa limitación temporal mientras que en los supuestos contencioso veremos como en los casos de custodia compartida la limitación temporal ha sido reconocida ampliamente y configurada como doctrina jurisprudencial.

Así, la ya citada sentencia del T.S., Sala de lo civil, 593/2014 de 24 de octubre, fijó la doctrina jurisprudencial de necesaria limitación temporal de atribución del uso de la vivienda familiar al progenitor no titular de la vivienda (no existía hasta ese momento sentencia alguna que resolviese sobre el tema objeto de recurso: atribución de guarda y custodia compartida y atribución por tiempo indefinido a la madre y al hijo del uso de la vivienda familiar por considerarlos el interés más necesitado de protección siendo dicha vivienda privativa del padre también custodio).

El Tribunal Supremo al analizar si debe o no imponerse una limitación al derecho de uso lleva a cabo la práctica de la ponderación de los intereses contrapuestos, en este caso el derecho del padre, titular de la vivienda, al cual se le privaría de todo derecho sobre ella al no poder disponer de la misma y, por otro lado, el derecho del hijo a comunicarse con la madre en otra vivienda. La conclusión a la que llega es que necesariamente ha de limitarse el uso, dicho limite temporal ha de ser durante el periodo de tiempo prudencial y necesario para que a quien se le haya atribuido el uso pueda acceder a una vivienda digna para atender a las necesidades del hijo durante los periodos de efectiva guarda.

A este respecto la STS 42/2017, de 23 de enero, recoge, en su fundamento de derecho segundo, la doctrina jurisprudencial sentada al respecto: remitiéndose la sentencia 2015/2016, de 6 abril. Doctrina que procedo a esquematizar en los siguientes puntos:

- $\quad$ Ausencia de regulación normativa específica en la materia.

- Los menores no se encuentran en compañía de uno solo de los progenitores sino de los dos, por lo que no resulta de aplicación el párrafo primero del artículo 96 del CC.

- De los dos puntos anteriores se desprende la necesaria aplicación analógica de párrafo segundo del artículo 96 del CC, esto es resolverá el Juez en atención a las circunstancias de cada caso. Para resolver debe necesariamente regirse por le interés más necesitado de protección.

- $\quad$ Cuando se fija la guarda y custodia compartida no cabe adscripción a la vivienda familiar de manera indefinida, porque no existe ya una residencia familiar sino dos. 
- $\quad$ Se hace necesaria una limitación temporal de la atribución del uso por cuanto sino se frustrarían toda posibilidad de disponibilidad de la vivienda bien del cotitular (progenitor a quien no se atribuye el uso) en caso de que la vivienda ganancial o bien de su titular cuando esta fuera privativa

La STS 513/2017, de 22 de septiembre, también concluye que no puede atribuirse indefinidamente a la madre el uso de la que fuera vivienda familiar a la madre y a la hija porque al alternarse la custodia entre padre y madre, la vivienda familiar no puede quedar adscrita a uno de ellos con exclusividad.

La reciente Sentencia del Tribunal Supremo, de fecha 7 de junio de 2018 que introduce la limitación temporal en la atribución del uso de la vivienda siendo esta ganancial y habiéndose optado dentro de la guarda y custodia compartida el sistema de casa nido, atribución del uso que se limita a la liquidación de la sociedad de gananciales. Importante nos parece esta sentencia porque difiere de las anteriores en que aquí la atribución del uso de la vivienda no se hacia uno solo de los progenitores sino a los menores debido precisamente a que se había otorgado la guarda y custodia compartida y el sistema de alternancia de la vivienda familiar por semanas, de ahí que la madre recurriese en casación en base que la limitación temporal del uso carecía de justificación al no haberse atribuido a uno solo de los progenitores sino a los hijos menores. Así el Supremo justifica la limitación y necesidad de acceder a dos viviendas de la siguiente manera: "En el caso, por acuerdo inicial de los progenitores en el momento de la separación, ambos se alternaron en el uso de la vivienda. Partiendo de que el interés de los menores justificaba la adopción de una custodia compartida, lo que ahora no se discute, la solución que se ha adoptado en las instancias es que los menores permanecieran en la vivienda, por ser su interés el más necesitado de protección, de acuerdo con el criterio general que resulta del art. 96 C.C. La sentencia recurrida determina que esta situación se mantendrá hasta que los exesposos liquiden la sociedad de gananciales y lo hace, como argumenta el Ministerio Fiscal, porque pondera las circunstancias: el interés más necesitado de protección, que en el caso es el de los menores, las tensiones que pueden producirse en su perjuicio con la excesiva prolongación de la situación de uso alterno de la vivienda y la conveniencia por ello de facilitar el tránsito a dos viviendas." El fundamento de la limitación temporal se fundamenta en el superior interés del menor, tratando de evitarlo de situaciones de tensión que puedan derivarse del prolongado uso alterno de la que fuera vivienda familiar.

Sobre este carácter temporal se pronuncia también el Anteproyecto de Ley sobre el ejercicio de la corresponsabilidad parental en caso de nulidad, separación y divorcio, en su artículo 8 al plantear la reforma del artículo 96 del Código Civil, contemplando precisamente su apartado tercero esta limitación temporal de la atribución del uso de la que fuera vivienda familiar. Y es que tal y como afirma José Domingo Forte, "se está formando un nuevo criterio jurisprudencial con finalidad y tendencia clara de buscar del equilibrio en las relaciones y en la posición de los padres con igual y compartida responsabilidad parental" 
Limitación temporal del uso que no sólo va a depender como reseñamos ab initio de este expositivo de la existencia o no de acuerdo de los cónyuges sino también de si la vivienda es privativa de uno solo de los cónyuges (en cuyo caso se fijará un tiempo prudencial), si es ganancial (generalmente se limita hasta la efectiva liquidación de la sociedad de gananciales), o si es propiedad de un tercero.

\section{CONCLUSIONES}

I. Ante la ausencia de normativa específica en materia de atribución de la vivienda familiar en guarda y custodia compartida la jurisprudencia ha concluido que no cabe la aplicación del artículo 96.1 del C.C. sino que debe necesariamente acudirse a una aplicación analógica del 96.4 del C.C., a la hora de atribuir el uso de la vivienda familiar y es que en este tipo de régimen de guarda y custodia ya no puede hablarse de la existencia de una vivienda familiar por cuanto el menor ya no queda al cuidado en exclusiva de uno solo de los progenitores sino de ambos y ya no habrá una única vivienda sino que habrán dos residencias salvo que se haya adoptado el sistema de casa nido, en cuyo caso existirán tres residencias, una de las cuales, la nido, será atribuida la hijo/os.

II. Es innegable que a la hora de decidir sobre la atribución del uso de la vivienda familiar el juez debe tener siempre presente el superior interés del menor pero no es menos cierto que existen otros intereses en juego que deben ser ponderados entre ellos el del titular o cotitular de la vivienda.

III. Atribuir indefinidamente el uso de la vivienda familiar a uno de los progenitores cuando se ha asignado un régimen de guarda y custodia compartida supone frustrar las expectativas del titular o cotitular de la misma, de ahí la imperiosa conveniencia de limitar en el tiempo dicha atribución dando así satisfacción a los intereses en conflicto: el de los hijos de disfrutar de ambos progenitores en una vivienda y el del titular o cotitular a quien no se ha atribuido el uso de la misma a poder disfrutar del que le pertenece.

IV. Del trabajo de investigación sólo podemos concluir que se hace necesaria una reforma del Código Civil y en concreto del artículo 96 para adaptar las vicisitudes que toda crisis matrimonial conlleva el sistema de guarda y custodia compartida y a sus distintas variantes.

\section{6. ÍNDICE DE LAS RESOLUCIONES CITADAS}

S.T.S., Sala Primera, N.:: 2014/2018, de 7 de junio de 2018, N. Rec.: 3553/2017.

S.T.S., Sala Primera, N.o: 181/2018, de 4 abril de 2018.

STS, Sala Primera, de 22 de septiembre de 2017 (SP/SENT/919434)

S.T.S., Sala Primera, N. 593/2014, de 24 de octubre de 2014. 
S.T.S, Sala Primera, №:576/2014, de 22 de octubre de 2014.

S.T.S., Sala Primera, N.o 215/2016, de 6 de abril de 2016, N. de recurso 1309/2015.

S.T.C. número 187/2012, de 17 de octubre de 2012.

\section{BIBLIOGRAFIA}

GETE ALONSO, M DEL CARMEN, SOLÉ RESINA, Judith y Calera, Custodia compartida. Derechos de los hijos y de los padres. Navarra, edit. Aranzadi S.A. 2015.

Guarda y custodia compartida: Criterios del Tribunal Supremo. Selección de Jurisprudencia. Madrid. Editorial Jurídica SEPIN S.L. (2018)

PEREZ CONESA, CARMEN, La custodia compartida. Navarra. Edit. Aranzadi S.A. 2016.

ESCUDERO BERZAL, B., "Custodia compartida: atribución vivienda familiar", Comunitania: Revista internacional de trabajo y ciencias Sociales, №.6, 2013, págs. 37-56.

MONFORTE, JOSÉ D., "Custodia compartida y vivienda familiar. La nueva doctrina Jurisprudencial", Diario la Ley, №.9012, Sección Tribuna, 3 de julio de 2017, Edit. Wolters Kluwer. 
